\title{
Suppression of Phytophthora Infection in Citrus Infected with Viroids
}

\author{
Tina P. Thomas, Madhurababu Kunta, John V. da Graça, \\ Mamadou Sétamou, and Mani Skaria ${ }^{1}$ \\ Texas A\&M University-Kingsville, Citrus Center, 312 N. International \\ Boulevard, Weslaco, TX 78596
}

\section{Apurba Bhattacharya \\ Texas A\&M University-Kingsville, Department of Chemistry, Kingsville, TX 78363}

Additional index words. exocortis, phenolic compounds, viroid-induced resistance, cachexia, CEVds, CVds

\begin{abstract}
Citrus viroid-induced resistance to Phytophthora infection in citrus was measured by the number of Phytophthora sporangia in 'Rio Red' grapefruit (Citrus paradisi Macf.) bait tissue infected with citrus viroids compared with non-inoculated controls. Different viroid isolates containing mixtures of viroids [Citrus exocortis viroid (CEVd), Hop stunt viroid (HSVd), Citrus viroid III (CVd-III), Citrus viroid IV (CVd-IV)] were designated by plant numbers and sources. Source $13 \mathrm{E}$ was associated with the lowest number of sporangia in bark, leaves, and roots used as baits, whereas CEVd E9, a known severe CEVd isolate, significantly reduced the number of sporangia in leaves and bark. Sources 1A, 2E, 3E, 4D, and $6 E$ showed a significantly reduced number of sporangia on bark, leaves, and roots compared with healthy plants and 44A; however, their effect was not as pronounced as that of E9 and 13E. Sources $12 \mathrm{E}$ and $44 \mathrm{~A}$ did not suppress sporangia production. Previous reverse transcriptase-polymerase chain reaction analysis showed that all source plants had mixed infections with several viroids, whereas $12 \mathrm{E}$ and $44 \mathrm{~A}$ contained no viroids. In addition to confirming the earlier reports on the suppression of Phytophthora infection in general, our study showed significantly reduced Phytophthora sporangia development resulting from a number of viroids in mixed infection, but there did not appear to be any effect related to viroid species. To determine if concentration affected resistance to Phytophthora, phenolic acids were extracted. Extraction of phenolic acids with $80 \%$ ethanol was more efficient compared with $100 \%$ methanol and an acetonitrile-water mixture. High-performance liquid chromatography revealed no notable detection of salicylic acid in healthy and viroidinfected plants, but there was a small peak corresponding to salicylic acid in Phytophthora-infected and both viroid and Phytophthora-infected plants. Flavone was detected in all the source plants with a slight increase in Phytophthora-infected and both viroid and Phytophthora-infected plants. A peak corresponding to quercetin dehydrate was detected in Phytophthora-infected plants. Efficient use of the right viroid isolate(s) can result in suppression of Phytophthora infection of citrus.
\end{abstract}

Root rot caused by Phytophthora nicotianae and $P$. citrophthora is one of the most serious and economically significant diseases of citrus (Graham and Timmer, 1994; Timmer and Menge, 1988). Phytophthora spp. can infect almost all parts of the citrus plant causing root rot, gummosis, and foot rot of the trunk; damping-off of seedlings; leaf blight; and brown rot of fruit. The use of resistant rootstock is an effective way to control Phytophthora infection. Quantitative evaluation of root rot susceptibility has indicated that trifoliate orange [Poncirus trifoliata (L.) Raf.] and

Received for publication 9 Dec. 2009. Accepted for publication 7 May 2009.

This project was supported by Texas A\&M University-Kingsville Citrus Center, Weslaco, TX. We thank all the staff members working in Texas A\&M University-Kingsville Citrus Center.

${ }^{1}$ To whom reprint requests should be addressed; e-mail MSkaria@ag.tamu.edu.
'Swingle citrumelo' (P. trifoliata $\times$ C. paradisi Macf.) are tolerant rootstocks (Widmer et al., 1988).

Viroids are infectious agents composed of covalently closed, single-stranded RNA molecules that undergo autonomous replication and have the ability to induce diseases in susceptible hosts (Diener and Raymer, 1971; Semancik, 1979). Citrus viroids are classified into: Citrus exocortis viroid (CEVd), Citrus bent leaf viroid (CBLVd), Hop stunt viroid (HSVd), Citrus viroid III (CVd-III), Citrus viroid IV (CVd-IV), and Citrus viroid $V$ (CVd-V) (Duran-Vila et al., 1988). Citrus viroids cause two economically important diseases, exocortis caused by CEVd and cachexia caused by HSVd (Roistacher, 1991). Exocortis was first described in 1948 as a bark-shelling or scaling disorder in trees grown on trifoliate orange and some of its hybrids (Benton et al., 1949; Fawcett and Klotz, 1948). Later, this disease was demonstrated to be graft-transmissible (Benton et al.,
1950; Fawcett and Klotz, 1948). Cachexia was first described in 1948 (Childs, 1950) with specific disease symptoms of discoloration, gumming, and browning of phloem and bark cracking on 'Orlando' tangelo (C. paradisi Macf. $\times C$. reticulata Blanco).

In Brazil, Rossetti et al. (1980) observed that exocortis-infected 'Hamlin' orange $[C$. sinensis (L.) Osb.] on Rangpur lime (C. limonia Osb.) rootstock resisted Phytophthora infection, but there were no consistent differences between the effects of mild and severe exocortis strains on Phytophthora lesions. Later, it was determined that the severe strains were exocortis and mild as were other viroids such as CVd-III.

Infection resulting from a pathogen induces changes in the host plant, including reinforcement of the cell wall by the formation of an impermeable deposit (Rossetti et al., 1980), accumulation of low-molecular-weight antifungal substances such as phytoalexins (Afeck and Sztejnberg, 1988), and the appearance of new pathogenesis-related proteins (Afeck and Sztejnberg, 1989; Antoniw et al., 1980). Some of the changes in the infection zone suggest that phenolic compounds may be the first line of defense (Matern and Kneusel, 1988) either as toxic products (free phenolic acids or their oxidation products, quinines) or as impedance in the invaded tissue (Bonhoff et al., 1987). An increase in phenols provides resistance for plants against fungal, bacterial, and viral infections (Matern and Kneusel, 1988). Soluble, low-molecular-weight phenolics are considered to have greater fungicidal activity compared with high-molecular-weight compounds (Harborne, 1989). Friend (1981) suggested that cell wall-bound phenolic acids alter the cell wall, creating a physical and chemical barrier against invading fungi. In citrus, phenolic compounds are produced in response to pathogen attack and stress factors such as ultraviolet radiation (Bonhoff et al., 1987; Broers and Jacobs, 1989; Manthey et al., 2000; Robbins, 1990). The production of antifungal phenolic compounds has been demonstrated in citrus fruits (Rodov et al., 1994), peels (Dubery et al., 1999), leaves (Harborne, 1989), and roots (Feldman and Hanks, 1968). Two antifungal compounds, xanthoxylin and scoparone, were found in the bark of lemon after infection with $P$. citrophthora (Afeck and Sztejnberg, 1988, 1989, 1990, 1993, 1995; Afeck et al., 1986). Scoparone accumulation was found to be responsible for resistance against collar rot caused by $P$. citrophthora. However, scoparone levels did not show strong relation to root rot resistance in response to infection by $P$. nicotianae (Aucamp et al., 2000).

In this study, we investigated the possible suppression of Phytophthora in citrus resulting from the presence of citrus viroids. Through high-performance liquid chromatography (HPLC), we evaluated the associated changes in the level of phenols in healthy compared with viroid-infected, Phytophthora-infected, and both Phytophthora and viroid-infected plants and investigated the levels of sporangia formation in each category of these plants. 


\section{Materials and Methods}

Plant material for inoculation of viroids. In this study, we used viroid source plants that were previously confirmed with the presence of the citrus viroids (Kunta et al., 2007b), including CEVd E9, an isolate that induces severe epinasty in Etrog citron $(C$. medica L.) (Baksh et al., 1984). Source plants 1A, 2E, 4D, and 13E contain CEVd, HSVd, and CVd-III, whereas 6E has all these viroids plus CVd-IV. Young leaves of source plants, 1A, 2E, 3E, 4D, 6E, 12E, 13E, non-inoculated control 44A, and healthy Rio Red grapefruit (C. paradisi Macf.) plants were collected, washed with water, dried, and weighed. The presence of viroids in these plants was previously confirmed by reverse transcriptionpolymerase chain reaction (RT-PCR) (Kunta et al., 2007b). Viroid extract was made by adding five times the weight of the leaves with deionized water and pulverizing the leaf tissue using a mortar and pestle. Young Rio Red grapefruit plants were inoculated with CEVd E9 viroid source by making slashes with a razor blade dipped in the viroid extract. The other sources were inoculated the same way. All the inoculation experiments were replicated three times. The inoculated plants were labeled and kept for 3 weeks in a greenhouse. Non-inoculated control plants were also kept under the same conditions. Seven of the inoculated plants were challenged with $P$. nicotianae by dipping the wounded plant roots in the liquid culture for $10 \mathrm{~min}$. Additionally, the P. nicotianae inoculum was poured into the root zone of the potted plants. The challenged plants were then kept for 4 more weeks to initiate Phytophthora infection.

Extraction of phenolic acids using highperformance liquid chromatography. Phenolic acids were extracted from CEVd E9-infected, Phytophthora-infected, and both viroid and Phytophthora-infected grapefruit on sour orange (Citrus aurantium L.) rootstock along with healthy control plants. Roots of these plants were washed with water, dried, and pulverized using a mortar and pestle. To this powder, an acetonitrile-water (50:50) mixture was added, vortexed, filtered, and injected into HPLC. The same procedure was followed using $100 \%$ ethanol. Additionally, to extract phenolic acids using $80 \%$ ethanol, the roots were washed with water, oven-dried for $40 \mathrm{~min}$ at $90{ }^{\circ} \mathrm{C}$, pulverized using a mortar and pestle, and stored at $4{ }^{\circ} \mathrm{C}$ until used. The powder $(0.2 \mathrm{~g})$ was treated with $80 \%$ ethanol for 6 to $7 \mathrm{~h}$ at $85{ }^{\circ} \mathrm{C}$. The solution was vortexed for $1 \mathrm{~min}$, sonicated for $5 \mathrm{~min}$, and centrifuged for $5 \mathrm{~min}$. The top layer of the solution was filtered twice using a cotton plug. Five milliliters of distilled water was added to this solution and subjected to rotoevaporation, and the residue was dissolved in $8 \mathrm{~mL}$ of $80 \%$ ethanol and injected into HPLC. The retention time for the peak was noted for and compared with a standard solution of known phenolic acid (Sigma-Aldrich, Milwaukee, WI). The solution corresponding to the salicylic acid, ferulic/gentisic acid, and flavone was collected for further analysis with Phytophthora.

Biological analysis. Phytophthora growth was compared in leaves, bark, and roots of viroid-infected and healthy plants of Rio Red grapefruit on sour orange (C. aurantium L.). Phytophthora nicotianae (Kunta et al., 2007a) was isolated from soil samples through a standard leaf bait routinely used in our laboratory (Kunta et al., 2007a). One milliliter of soil suspension and leaf discs were also transferred to selective agar media plates with a final concentration of antibiotics $10 \mathrm{mg} \cdot \mathrm{L}^{-1}$ pimaricin, $200 \mathrm{mg} \cdot \mathrm{L}^{-1}$ vancomycin, $100 \mathrm{mg} \cdot \mathrm{L}^{-1}$ pentachloronitrobenzene, and $50 \mathrm{mg} \cdot \mathrm{L}^{-1}$ hymexazole. A gel slice with Phytophthora hyphae was transferred to V8 juice medium for further growth of the fungus and incubated in an incubator under dark at $15.4^{\circ} \mathrm{C}$ for $2 \mathrm{~d}$. The Phytophthora sporangia containing gel with the V8 juice medium was transferred to water and kept for $2 \mathrm{~d}$. The zoospore release was induced by chilling the sporulating culture for $1 \mathrm{~h}$ and then keeping at room temperature for another hour. The zoospores were counted using a hemacytometer (Bright-Line; American Optical Corporation, Buffalo, NY). The leaves, bark, and roots of the viroidinfected and healthy plants were baited with $600 \mu \mathrm{L}\left(\approx 2 \times 10^{5}\right.$ zoospores $)$ of the zoospore solution of Phytophthora. Grapefruit leaf discs were used in leaf and bark assay and sour orange for root assay. After $4 \mathrm{~d}$ of incubation, the sporangia were counted under a microscope. The results of sporangial production in viroid-infected and healthy leaf discs were compared. The comparison of the effect of sporangial production between leaf, bark, and root tissue of viroid-infected and control grapefruit plants is represented in graphs using Sigma Plot.

Testing phenol effects on Phytophthora sporangia formation. The phenolic acids collected by HPLC, flavone, salicylic acid, and gentisic acid, ferulic acid, were used to study the effects at different concentrations on sporangia formation. A $600-\mu \mathrm{L}$ zoospore suspension was added to each $2 \mathrm{~mL}$ of the phenol solutions of series of 10 -fold dilutions ranging from $1 / 10,1 / 100,1 / 1,000,1 / 10,000$, to $1 / 100,000$. These were then used to bait Rio Red grapefruit leaf discs. After $4 \mathrm{~d}$ of inoculation, the number of sporangia was counted in each phenol solution at different concentrations.

Data analysis. In the first experiment, all the Phytophthora sporangia present in leaves, bark, and roots were counted. In the subsequent experiments, all the plant parts with more than 100 sporangia were scored as "100+." In the data analysis, all "100+" scores were replaced by the average value of observations with more than 100 sporangia in the first experiment; the data were analyzed with the generalized linear model procedure (Proc GLM) of statistical analysis software (SAS Institute Inc., Cary, NC), and means were compared with the least significant difference method at $P=0.05$. All sporangia counts were $\log (\mathrm{x}+1)$ transformed before analysis. The numbers of sporangia on leaves, barks, and roots between the viroids and the untreated control were compared by analysis of variance. The significant F-values were obtained; treatment means were separated using the Student Newman Keuls test.

\section{Results and Discussion}

In most of the healthy, viroid-infected, and Phytophthora-infected plants, a peak corresponding to ferulic acid was detected in HPLC analysis. There was a slight difference in peak area in both viroid and Phytophthora-infected plants. There was no notable detection of salicylic acid in healthy and

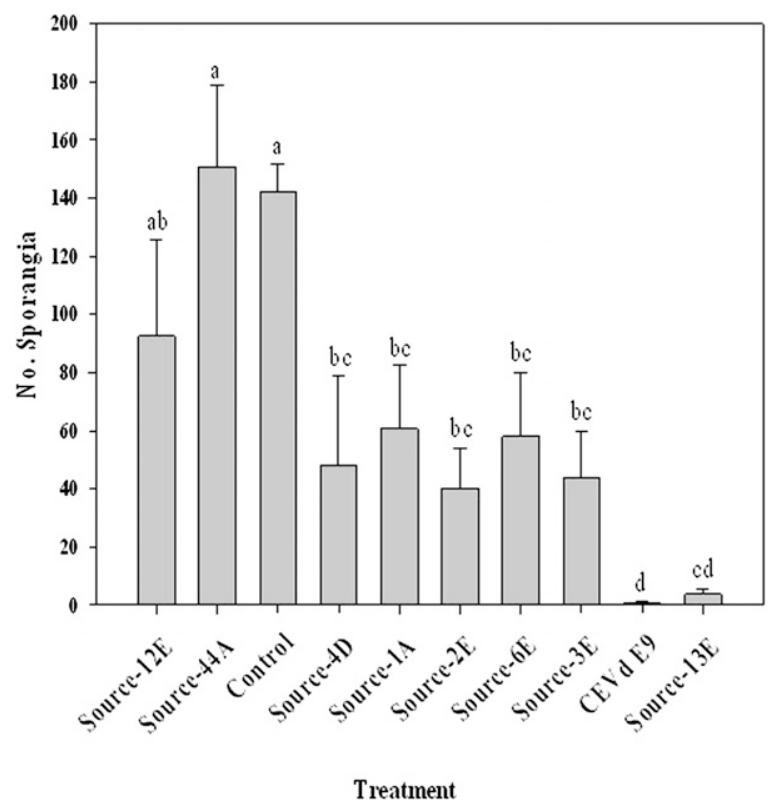

Fig. 1. Number of sporangia counted on leaves of grapefruit plants treated with different sources versus control (means followed by the same letter are not significantly different at $P=0.05$, Student Newman Keuls test). 
viroid-infected plants, but there was a small peak corresponding to salicylic acid in Phytophthora-infected and viroid- and Phytophthora-infected plants. Flavone was detected in all healthy, viroid-infected, Phytophthora-infected and both viroid-and Phytophthora-infected plants. However, there was a slight increase in the peak area of flavone in Phytophthora and both viroid- and Phytophthora-infected plants. A peak corresponding to quercetin dehydrate was detected in Phytophthora-infected plants.

Citrus viroid-induced tolerance to Phytophthora infection was measured by the number of Phytophthora sporangia in a group of seven Rio Red grapefruit plants on sour orange rootstock infected with citrus viroids and a non-inoculated control. Previous RTPCR results showed that all the source plants have mixed infections with several viroids, whereas source plants $12 \mathrm{E}$ and $44 \mathrm{~A}$ contained no viroids (Kunta et al., 2007b). There was a significant reduction in the number of Phytophthora sporangia in leaves, roots, and bark of viroid-infected plants compared with the healthy control. The number of Phytophthora sporangia varied with treatments on leaves $(\mathrm{F}=19.29 ; \mathrm{df}=9,326 ; P<0.0001)$ (Fig. 1), roots $(\mathrm{F}=25.45 ; \mathrm{df}=8,271, P<$ 0.0001) (Fig. 2), and bark $(\mathrm{F}=18.23$; $\mathrm{df}=9$, 312; $P<0.0001$ ) (Fig. 3). Plants infected with $13-E$ had the lowest number of sporangia in all three plant parts. The number of sporangia counted on leaves and bark of grapefruit infected with the CEVd isolate E9 was comparable to that of the source plant 13E. Treatment with source 44-A did not affect the number of sporangia compared with the untreated control on all three plant parts. Treatment with source $12 \mathrm{E}$ only significantly reduced the number of sporangia on roots and not on the bark and leaves. Although infection with the sources $1 \mathrm{~A}, 3 \mathrm{E}, 4 \mathrm{D}, 2 \mathrm{E}$, and $6 \mathrm{E}$ significantly reduced the number of sporangia relative to the control on leaves, bark, and roots, their effects were not as pronounced as those of the plant 13E and CEVd E9.

In all the experiments to detect differences in phenolic acids, flavone, salicylic acid, and gentisic acid/ferulic acid, it had been observed that at higher concentrations found, no sporangia were produced and at lower concentrations, the sporangia production increased drastically. However, there was not much difference in the number of sporangia produced with different phenolic acids. All inoculations were successful in producing infection based on RT-PCR analyses (Kunta et al., 2007b). The results obtained in this study and the statistical analyses clearly show that grapefruit plants infected with citrus viroids suppressed the formation of Phytophthora sporangia, especially with sources $13 \mathrm{E}$ and CEVd E9 plants. The results also suggest that there can be a possible relation between the concentration difference of phenolic acids in plants when they are infected with citrus viroids and Phytophthora. The results also show that there is a difference in the quantity of salicylic acid, flavone, and quercetin dihydrate in control, viroid-infected, Phytophthora-infected and

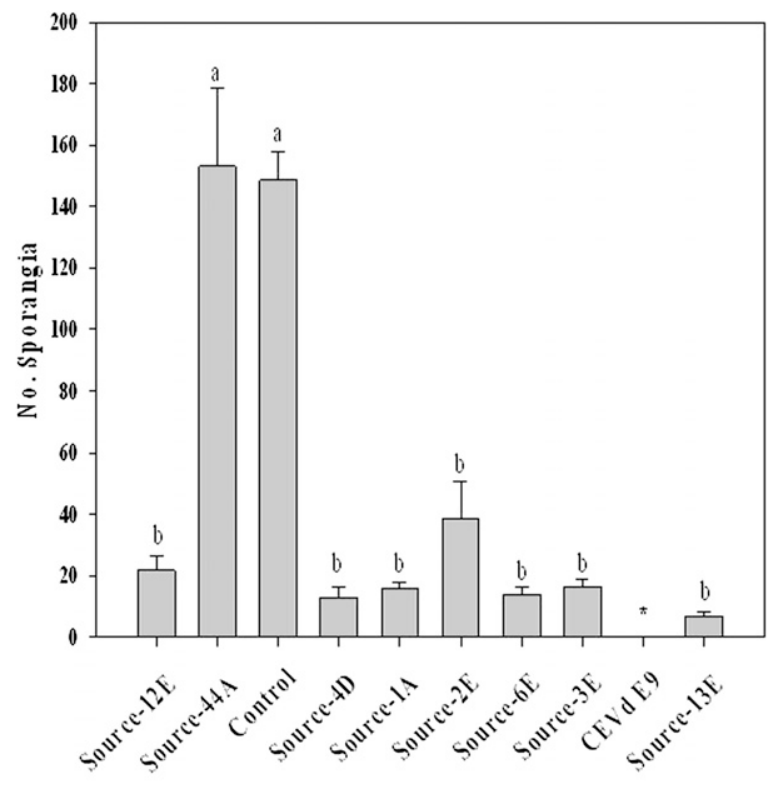

Treatment

Fig. 2. Number of sporangia counted on roots of sour orange rootstock treated with different sources versus control (means followed by the same letter are not significantly different at $P=0.05$, Student Newman Keuls test; *experiment not done).

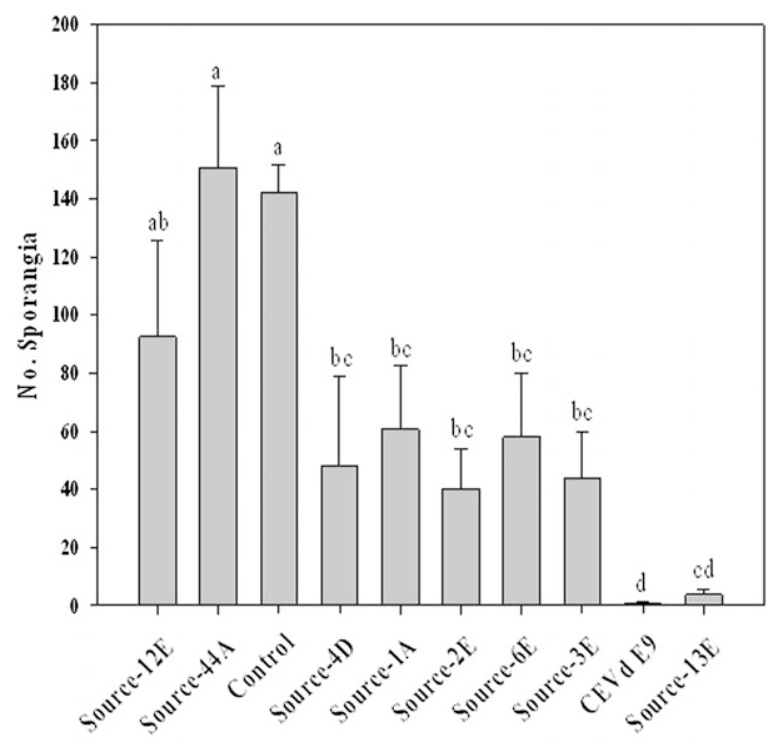

Treatment

Fig. 3. Number of sporangia counted on bark of grapefruit plants treated with different sources versus control (means followed by the same letter are not significantly different at $P=0.05$, Student Newman Keuls test).

both viroid and Phytophthora-infected plants. Moreover, it is found that all the viroids may confer some degree of suppression against Phytophthora.

Rosetti et al. (1980) had observed that Phytophthora lesion size on Rangpur lime did not differ when plants were infected with a mild or severe exocortis strain(s). In our study, there was also no apparent effect related to viroid species. Although E9 (CEVd E9 only)-infected tissues had the lowest number of sporangia, the presence or absence of HSVd, CVd III, and CVd IV did not significantly affect the number of sporangia. The only anomaly was in 12E-inoculated roots, in which a reduction of sporangia was found although inoculation was not successful (no viroid could be detected by RT-PCR). Citrus viroid-induced resistance of grapefruit plants toward Phytophthora may result in viroid-based control when the mechanism is fully understood.

\section{Literature Cited}

Afeck, U. and A. Sztejnberg. 1988. Accumulation of scorpane, a phytoalexin associated with 
resistance of citrus to Phytophthora citrophthora. Phytopathology 78:1678-1682.

Afeck, U. and A. Sztejnberg. 1989. Effects of fosetyl-Al and phosphorous acid on scorpane, a phytoalexin associated with resistance of citrus to Phytophthora citrophthora. Phytopathology 79:736-739.

Afeck, U. and A. Sztejnberg. 1990. A rapid method for evaluating citrus seedlings for resistance to foot rot caused by Phytophthora citrophthora. Plant Dis. 74:66-68.

Afeck, U. and A. Sztejnberg. 1993. Temperature and gamma irradiation effects on scorpane, a citrus phytoalexin conferring resistance to Phytophthora citrophthora. Phytopathology 83:753-758.

Afeck, U. and A. Sztejnberg. 1995. Scorpane (6, 7-dimethoxycoumarin), a citrus phytoalexin involved in the resistance to pathogens, $p$. 263-286. In: Daniel, M. and R.P. Purkayastha (eds.). Handbook of phytoalexin metabolism and action. Marcel Dekker Inc, New York, NY.

Afeck, U., A. Sztejnberg, and S. Carmely. 1986. 6, 7-dimethoxycoumarin, a citrus phytoalexin conferring resistance against Phytophthora gummosis. Phytochemistry 25:1855-1856.

Antoniw, J.F., C.E. Ritter, W.S. Pierpoint, and L.C. Van Loon. 1980. Comparison of three pathogenesis-related proteins from plants of two cultivars of tobacco infected with TMV. J. Gen. Virol. 47:79-87.

Aucamp, J.P., S.S. Kotze, A. Fourie, N. Labuschagne, and Z. Apostolides. 2000. Determination of scorpane in citrus roots by micellar electrokinetic capillary chromatography. J. High Resolut. Chromatogr. 23:519-521.

Baksh, N., R.F. Lee, and S.M. Garnsey. 1984. Detection of exocortis viroid by polyacrylamide gel electrophoresis. Proc. 9th Conf. IOCV. p. 343-353. IOCV, Riverside, CA.

Benton, R.J., F.T. Bowman, L. Fraser, and R.G. Kebby. 1949. Stunting and scaly butt of citrus associated with Poncirus trifoliata rootstock. Agri. Gaz. NSW 60:521-526, 577-582, 641$645,654$.

Benton, R.J., F.T. Bowman, L. Fraser, and R.G. Kebby. 1950. Stunting and scaly butt associ- ated with Poncirus trifoliata rootstock. N.S.W. Dept. Agr. Sci. Bull. 70:1-20.

Bonhoff, A., B. Rieth, J. Golecki, and H. Grisebach. 1987. Race: Cultivar-specific differences in callose deposition in soybean roots following infection with Phytophthora megasperma f.sp. glycinea. Planta 172:101-105.

Broers, L.H.M. and T.H. Jacobs. 1989. The inheritance of host plant effect on latency period of wheat leaf rust in spring wheat. II. Number of segregating factors and evidence for transgressive segregation in F3 and F5 generations. Euphytica 44:207-214.

Childs, J.F.L. 1950. The cachexia disease of Orlando tangelo. Plant Dis. Rep. 34:295-298.

Diener, T.O. and W.B. Raymer. 1971. Descriptions of plant viruses. No. 66. CMI/AAB, Kew, Survey, UK.

Dubery, I.A., A.E. Louw, and F.R. Van Heerden. 1999. Synthesis and evaluation of 4-(3methyl-2-butenoxy) isonitrosoacetophenone, a radiation-induced stress metabolite in citrus. Phytochemistry 50:983-989.

Duran-Vila, N., C.N. Roistacher, R. RiveraBustamante, and J.S. Semancik. 1988. A definition of citrus viroid groups and their relationship to the exocortis disease. J. Gen. Virol. 69:3069-3080.

Fawcett, L.R. and L.J. Klotz. 1948. Bark shelling of trifoliate orange. Calif. Citrograph 48:230.

Feldman, A.W. and R.W. Hanks. 1968. Phenolic content in the roots and leaves of tolerant and susceptible citrus cultivars attacked by Radopholus similis. Phytochemistry 7:5-12.

Friend, J. 1981. Plant phenolics, lignification and plant disease, p. 197-261. In: Reinhold, L., J.B. Harborne, and T. Swain (eds.). Progress in phytochemistry. Pergamon Press, Oxford, UK.

Graham, J.H. and L.W. Timmer. 1994. Phytophthora diseases of citrus. Uni. Florida, IFAS Extension, SL127.

Harborne, J.B. 1989. General procedures and measurement of total phenolics, p. 1-28. In: Harborne, J.B. (ed.). Methods in plant biochemistry. Academic Press, New York, NY.
Kunta, M., M. Hongqin, and M. Skaria. 2007a. Molecular distinction of citrus Phytophthora isolates in the lower Rio Grande Valley of Texas. Subtropical Plant Sci. 58:1-5.

Kunta, M., J.V. da Graça, and M. Skaria. 2007 b. Molecular detection and prevalence of citrus viroids in Texas. HortScience 42:600-604.

Manthey, J.A., K. Grohmann, M.A. Berhow, and B. Tisserat. 2000. Changes in citrus leaf flavanoid concentrations resulting from blightinduced zinc-deficiency. Plant Physiol. Biochem. 38:333-343.

Matern, U. and R.E. Kneusel. 1988. Phenolic compounds in plant disease resistance. Phytoparasitica 16:153-170.

Robbins, R. 1990. Medical and nutritional aspects of citrus bioflavanoids, p. 43-59. In: Nagy, S. and J. Attaway (eds.). Citrus nutrition and quality. American Chem. Soc., Washington, DC.

Rodov, V., S. Ben-Yehishua, D. Fang, G. Hallewin, and T. Castia. 1994. Accumulation of phytoalexins scorpane and scopoletin in citrus fruits subjected to various post harvest treatments. Acta Hort. 381:517-523.

Roistacher, C.N. 1991. Graft-transmissible diseases of citrus: Handbook for detection and diagnosis. FAO, Rome, Italy.

Rossetti, V., J. Pompeu, J.O. Rodriquez, M.H Vechiato, M.L. da Veiga, D.A. Oliveira, and J.T. Sobrinho. 1980. Reaction of exocortisinfected and healthy trees to experimental Phytophthora inoculations. Proc. 8th Conf. IOCV. p. 209-214. IOCV, Riverside, CA.

Semancik, J.S. 1979. Small pathogenic RNA in plants. Viroids. Ann. Rev. Phytopathol. 17: 461-481.

Timmer, L.W. and J.A. Menge. 1988. Phytophthorainduced diseases, p. 43-59. In: Whiteside, J.O., S.M. Garnsey, and L.W. Timmer (eds.). Compendium of citrus diseases. APS Press, St. Paul, $\mathrm{MN}$.

Widmer, T.L., J.H. Graham, and D.J. Mitchell. 1988. Histological comparison of fibrous root infection of disease-tolerant and susceptible citrus hosts by Phytophthora nicotianae and P. palmivora. Phytopathology 88:389-395. 